\title{
FORMAÇÃO DE PROFESSORES: DESAFIOS NA MELHORIA DO PROCESSO ENSINO E APRENDIZAGEM
}

\section{TEACHER TRAINING: CHALLENGES IN IMPROVING THE TEACHING AND LEARNING PROCESS}

\section{Artur Romão Rocha iD}

Bacharel em Ciências Contábeis pela Universidade do Norte do Paraná UNOPAR. Docente na Faculdade de Educação e Meio Ambiente - FAEMA, Ariquemes/RO.

E-mail: arturromaorocha@gmail.com.

Submetido: 15 nov. 2021.

Aprovado: 8 dez. 2021.

Publicado: 15 dez. 2021.

E-mail para correspondência: arturromaorocha@gmail.com

Este é um trabalho de acesso aberto e distribuído sob os Termos da Creative Commons Attribution License. A licença permite o uso, a distribuição e a reprodução irrestrita, em qualquer meio, desde que creditado as fontes originais.

Imagem: StockPhotos (Todos os direitos reservados).

Open Access
Resumo: 0 presente artigo tem como objetivo abordar a formação continuada de professores e os desafios na melhoria do processo ensino e aprendizagem, tendo em vista que este é um tema que tem sido objeto de debates nos contextos acadêmicos e políticas educacionais. Nesse sentido, ao considerar os desafios colocados no atual contexto educacional frente ao resgate de uma concepção de formação continuada de professores a partir de uma visão dialógica e crítica que considere as necessidades e peculiaridades dos professores, torna-se necessário ressaltar a importância da formação continuada se consolidar como parte integrante do trabalho docente e para a necessidade de novos estudos que ultrapassem a distância entre teoria e prática.

Palavras-chave: Formação Continuada. Escola. Ensino-aprendizagem

Abstract: This article aims to address the continuing education of teachers and the challenges in improving the teaching and learning process, considering that this is a topic that has been the subject of debate in academic contexts and educational policies. In this sense, when considering the challenges posed in the current educational context facing the rescue of a concept of continuing education for teachers from a dialogical and critical view that considers the needs and peculiarities of teachers, it is necessary to emphasize the importance of continuing education to consolidate itself as an integral part of teaching work and to the need for new studies that bridge the gap between theory and practice

Keywords: Continuing Education. School. Teaching-learning.

\section{Introdução}

Nos últimos anos, as discussões giram em torno da importância da formação continuada de professores e da necessidade de uma formação que ofereça embasamento para 


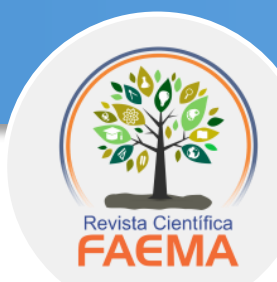

trabalho do professor a partir de uma mediação entre teoria e prática considerando as constantes mudanças e demandas educacionais. Nesse sentido, a Lei Federal $\mathrm{n}^{\circ}$ 9.394/96 dispõe sobre a necessidade da formação continuada tendo em vista a melhoria do processo educacional (1).

Entretanto, segundo Freitas e Pacífico ${ }^{(2)}$, a formação continuada ainda é um desafio para muitos professores e para o sistema educacional. A formação acadêmica inicial não garante total preparação do professor. Assim, entende-se que o crescimento da consciência política na atuação pedagógica acontece a partir da construção de novos saberes a partir de uma relação entre prática e teoria, a partir de uma constante transformação e compromisso do professor com sua competência técnica e profissional (3).

Nesse sentido, a formação continuada é um processo complexo e requer novas abordagens a partir de uma visão crítica em que o professor possa vivenciar a teoria da formação inicial e a prática do cotidiano escolar de uma forma dialética, na construção de novos saberes, contribuindo de forma significativa para o avanço e melhoria do processo ensino e aprendizagem na escola (3).

\section{Breve abordagem da Formação Continuada de professores no Brasil}

Ao abordar a formação continuada de professores no Brasil, segundo Costa e Cruz (3), no período colonial, a Companhia de Jesus chegou ao Brasil em meados de 1549, liderada pelo padre Manuel da Nóbrega que tinha como objetivo escravizar os índios sob o pretexto de converter os nativos à fé cristã e dar continuidade aos ensinamentos da igreja.

Os missionários da Companhia, conhecidos como Jesuítas, estiveram em várias partes do mundo, foram educadores e catequizadores e assim, introduziram a prática de formação de professores a partir de métodos de instrução absolutos e uniformes para todos os professores com o objetivo de garantir a eficiência do sistema ${ }^{(3)}$. Assim, entende-se que os jesuítas foram os primeiros a trazer a ideia da necessidade de formação em serviço para os professores ${ }^{(4)}$. 


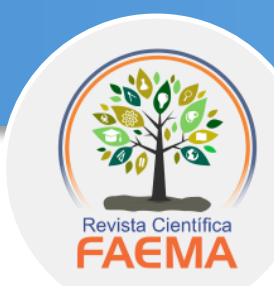

Nesse contexto, entretanto, nota-se que:

[...] a educação instaurada no âmbito do processo de colonização, trata-se, evidentemente, de aculturação, já que as tradições e os costumes que se busca inculcar decorrem de um dinamismo externo, isto é, que vai do meio cultural do colonizador para a situação de objeto de colonização (SAVIANI, 2008, p. 27) ${ }^{(4)}$.

Dessa forma, observa-se que nesse período, a formação de professores já era motivo de preocupação, uma vez que a educação tinha como objetivo a aculturação dos indígenas, tornando-os objeto de colonização sob o domínio da elite.

$\mathrm{Na}$ década de 1970, os cursos de formação continuada de professores, de acordo com Freitas e Pacífico (2), tinham como foco o método de treinamento dos professores, os currículos eram mais focados nas dimensões técnicas, treinamentos em serviço ou reciclagem. A partir da década de 80 , o modelo de formação focada somente na técnica ganhou repercussão e recebeu críticas, considerando que esse modelo não atendia as necessidades dos professores em serviço.

Nesse sentido, de acordo com Freitas ${ }^{(5)}$, no final dos anos 70 e início da década de 1980, a formação de professores passou por reformulação travadas no âmbito oficial que entendia a formação de professores como uma questão de formação de recursos humanos para a educação a partir de uma visão tecnicista. Entretanto, os anos 80 representaram a ruptura com o pensamento tecnicista que predominava na época com uma nova proposta de formação de professores.

O momento exigia a necessidade um profissional de caráter amplo, com pleno domínio e compreensão da realidade de seu tempo, com desenvolvimento da consciência crítica que lhe permitisse interferir e transformar as condições da escola, da educação e da sociedade (5).

Assim, ao observar a trajetória do professor, nota-se que ele sempre sofreu influências com as transformações ocorridas no campo cultural, social, econômico e político da sociedade ${ }^{(5)}$. Ao tratar da luta dos educadores a partir do final dos anos 70 e início da década de 1980 pela democratização da sociedade, de acordo com Freitas ${ }^{(5)}$ pode-se afirmar que: 


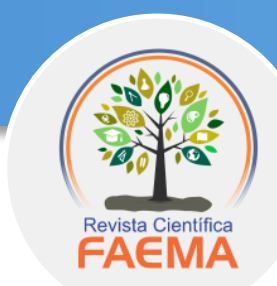

[...] trouxe contribuições importantes para a educação e para a forma de olhar a escola e o trabalho pedagógico, ao colocar em evidência as relações de determinação existentes entre educação e sociedade e a estreita vinculação entre a forma de organização da sociedade, os objetivos da educação e a forma como a escola se organiza (FREITAS, 2002, p.138) ${ }^{(5)}$.

A década de 90, de acordo com Freitas ${ }^{(5)}$, denominada como a nova "Década da Educação", aprofundou as discussões em torno da melhoria da formação de professores e a importância de estratégias para a realização das reformas educativas.

Nesse sentido, as principais estratégias no Governo Fernando Henrique Cardoso foi a distribuição das verbas federais diretamente para as escolas, sem passar pelos Estados e Municípios; criação do Sistema Nacional de Educação à Distância, com a instalação de aparelhos de TV em cada escola, com o objetivo de preparar os professores; melhoria da qualidade dos livros didáticos distribuídos para as escolas; reforma do currículo escolar e a avaliação das escolas por meio de testes, premiando aquelas com melhor desempenho.

No que se refere ainda, a formação continuada de professores na década de 90 , pode-se afirmar que:

\begin{abstract}
Apesar dos avanços ocorridos na década de 1990, quanto à forma de conceber a formação continuada de professores, grande parte dos programas de formação do Brasil ainda vem se pautando em uma tendência liberal-conservadora, inspirada numa perspectiva homogeneizadora, autoritária, instrumental e de base acadêmica e teórica [...]. O professor é reduzido a reprodutor de conhecimentos já instituídos, cumprindo apenas os programas decididos por especialistas que nem sequer conhecem a realidade cotidiana da escola e sentido (FREITAS; PACÍFICO apud SILVA, 2007, p. 105) ${ }^{(2)}$.
\end{abstract}

Entretanto, de acordo com Peroni (6), a partir da década de 90, observa-se se a presença cada vez maior do privado mercantil que define as propostas e os rumos da educação pública. Assim, o Estado continua o responsável pelo acesso, e ampliação das vagas públicas, mas, no entanto, o conteúdo pedagógico, a gestão da escola entre outras estratégias, são cada vez mais determinados por instituições a partir da lógica mercantil em torno de uma discussão de melhoria e avanço da qualidade da educação pública ${ }^{(6)}$. 


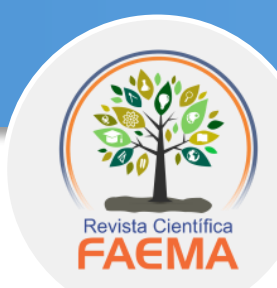

Nesse sentido, ao analisar a formação de professores nos últimos anos, segundo Freitas (5), é importante destacar que os modelos de formação, bem como a política de expansão dos institutos superiores de educação e cursos normais superiores, desde 1999, seguem as recomendações do Banco Mundial e outros organismos financiadores internacionais caracterizados como instituições de caráter técnico-profissionalizante, como objetivo principal a formação de professores com ênfase no caráter técnico instrumental, com competências determinadas para solucionar problemas da prática cotidiana.

De acordo com Freitas ${ }^{(5)}$, a luta pela democratização da sociedade brasileira passa pela necessidade de uma gestão democrática da escola e em todos os níveis da educação, inclusive a luta pela autonomia da universitária que incluí a descentralização do poder de decisão na área da educação.

Considerando que o Estado tem se manifestado de forma descomprometida com educação com a retirada de recursos públicos e a falta da manutenção e estruturação das instituições públicas de ensino.

\section{Formação Continuada: definições e concepções}

Ao tratar do conceito de formação continuada, segundo Freire ${ }^{(7)}$, a formação é um fazer permanente que se refaz constantemente na ação, a formação não se dá apenas por acúmulos de conhecimentos, mas em conquistas construídas com as várias leituras, mestres, das conversas entre professores, ouso das mídias e tantos outros meios. Nesse sentido, a formação está associada ao desenvolvimento pessoal e profissional.

Entretanto, ao fazer uma análise da terminologia de formação, segundo Altenfelder (8), existem diferentes concepções, originadas em diferentes pressupostos filosóficos, epistemológicos e metodológicos, coexistem e se confrontam no campo da formação continuada. Nesse sentido, não é possível pensar a formação de professores sem uma análise crítica que possibilite pensar a serviço de que estão as ações de formação e em que medida podem caminhar na superação da distância entre teoria e prática ${ }^{(8)}$. 


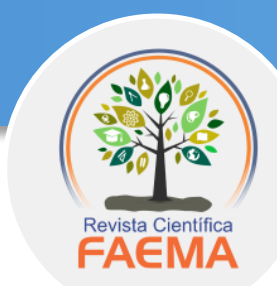

Nesse sentido, é possível afirmar que:

A formação inicial refere-se ao ensino de conhecimentos teóricos e práticos destinados à formação profissional, completados por estágios. A formação continuada é o prolongamento da formação inicial, visando o aperfeiçoamento profissional teórico e prático no próprio contexto de trabalho e o desenvolvimento de uma cultura geral mais ampla, para além do exercício profissional (LIBÂNEO, 2004, p. 227) ${ }^{(9)}$.

Para Libâneo (9), a formação acadêmica é uma etapa inicial importante para o futuro professor, no entanto, o docente deve estar disposto a inovar, buscar um diferencial para suas aulas, através de uma prática pedagógica que utilize o lúdico e o concreto, estimulando o aluno em sua aprendizagem, fazendo com que o estudante ligue o conteúdo à prática. Nesse contexto, a formação continuada se torna extremamente importante.

No entanto, apesar do esforço e dedicação dos professores, pode-se destacar que:

[...] em seu ambiente de trabalho, se sentem impossibilitados em despertar a curiosidade de seus alunos e fazer com que mantenham atenção em suas aulas, ter o controle sobre a turma, tornar as aulas mais interessantes, com propostas inovadoras. Contudo, essas situações descritas podem causar, ao docente, muito desânimo e/ou a falta de estímulos necessários para planejar devidos conteúdos escolares e, dessa forma, muitos se sentem desmotivados a continuar no desenvolvimento de seu ofício (RODRIGUES et al, 2017, p.29) (10).

Para Pimenta ${ }^{(11)}$, os programas de formação devem se constituir como espaço em que os professores possam reelaborar os saberes adquiridos na formação inicial com as experiências de suas práticas docentes, ou seja, um grande processo de vivenciar a teoria da formação inicial e a prática do cotidiano escolar de uma forma dialética. Nesse contexto, os professores coletivamente têm a oportunidade de construção de novos saberes que envolve a formação autônoma e a reelaboração contínua de novos saberes, partindo da vivência prática do espaço escolar (11).

A formação de professores é um processo complexo que exige um entendimento a partir da seguinte questão: 


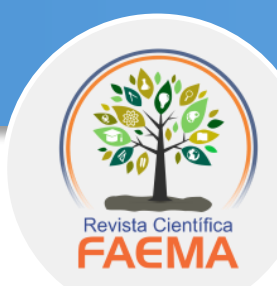

[...] a formação e profissionalização docentes são aspectos indissociáveis e que estão profundamente imbricados na escolha da profissão, na forma de ingresso no campo de atuação, no acolhimento no local de trabalho, nas formas de organização e produção do trabalho escolar, no grau de satisfação profissional com a carreira e com a profissão e nas perspectivas de crescimento e desenvolvimento profissional ao longo da vida (GUIMARÃES, 2006, p.111) ${ }^{(12)}$.

Formação, de acordo com Garcia (13), se apresenta como um fenômeno complexo e diverso tendo em vista que o conceito de formação não se identifica nem se dilui dentro de outros conceitos como educação, ensino treino, entre outros. Mas o conceito formação inclui uma dimensão pessoal de desenvolvimento humano global e principalmente com a vontade de formação.

Assim, pode-se destacar que “[...] durante o processo de formação, o docente adquire experiência e conhecimento que o transforma, ou seja, na sua maneira de pensar e agir" (7). No entanto, entende-se que o professor enfrenta uma época de muitas transformações e desafios. Nesse contexto pode-se enfatizar que:

[...] não é fácil, no Brasil, sobreviver dessa profissão (salários baixos, jornada extensa e condições materiais difíceis) nem, tampouco sobreviver nessa profissão, considerando o desgaste físico, emocional e cultural (pouco tempo e estímulo para se atualizar) a que os professores são, em geral, expostos em sua trajetória profissional. Essa realidade torna-se bem mais explicita diante das recorrentes "novas exigências "criadas para cumprimento pelos professores. Nesse contexto, não é fácil o professor desenvolver uma imagem positiva da profissão docente (GUIMARÃES, 2006, p. 90) ${ }^{(12)}$.

Para compreender a complexidade desta temática, de acordo com Freitas e Pacífico (2), é importante adentrar o espaço escolar, identificar quais são os desafios e as possibilidades para efetivar a formação continuada daqueles que atuam na escola e assim, propor junto aos professores e à equipe pedagógica da escola a elaboração coletiva de um plano de ação que possa contribuir com a efetivação da formação continuada dentro do espaço escolar. 


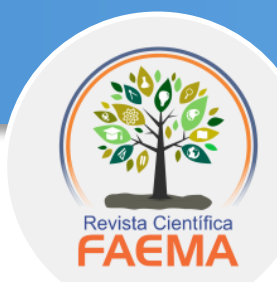

Dessa forma, pode-se destacar que:

O que se deve mover para a discussão dessa temática e o empenho na formação desse profissional é a convicção de que a educação é processo imprescindível pra que o homem sobreviva e se humanize e de que a escola é instituição ainda necessária nesse processo. Enfim, a relevância dessa temática está na compreensão da urgência, da complexidade e da utopia do projeto de qualidade para uma sociedade efetivamente mais democrática (GUIMARÃES, 2006, p. 31) ${ }^{(12)}$.

Observa-se que a formação continuada de professor pode ser entendida como uma atividade de mediação, entre docente e discente na construção de estratégias para ensinar e aprender ${ }^{(12)}$.

\section{Formação Continuada e os desafios da melhoria do ensino}

Nos últimos anos, segundo Altenfelder ${ }^{(8)}$, com a democratização da escola pública e consequentemente o aumento do número de matrículas, é cada vez mais crescente a preocupação com a melhoria da qualidade da educação, principalmente na escola pública. Para que a escola atenda esse desafio, cumprindo efetivamente sua função de ensinar e formar cidadãos, é urgente a necessidade de mudanças na sua estrutura, organização e principalmente nas práticas pedagógicas dos professores em sala de aula ${ }^{(8)}$.

Ao tratar dos investimentos na educação, de acordo com Ruggeri (14), apesar dos investimentos a partir de programas de formação de educadores, livros didáticos, obras literárias e obras de referência para formação teórica dos professores e gestão. E ainda campanhas e expansão do uso do acervo do PNDL - Plano Nacional do Livro Didático e o PNBE - Programa Nacional Biblioteca da Escola que estimula a leitura; incentivo à Política Nacional de Formação de Professores da educação Básica, Universidade Aberta do Brasil entre outros. O Brasil ainda enfrenta o grande desafio de alfabetizar todas as crianças e elevar o nível de proficiência da leitura e escrita dos estudantes em todos os níveis de ensino da educação básica ${ }^{(14)}$. 


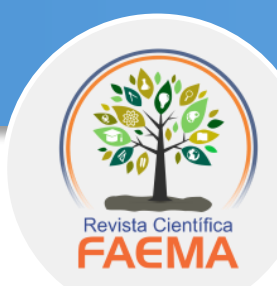

O fracasso escolar, segundo Soares ${ }^{(15)}$, tem avançado de forma significativa e agravante, atingindo uma grande parcela dos estudantes brasileiros. 0 baixo desempenho escolar é revelado nas avaliações externas nacionais como o SAEB e ENEM. Os resultados dessas avaliações se traduzem nos altos índices de baixa proficiência de leitura, escrita e cálculo matemático.

A maioria dos jovens e adolescentes chegam ao ensino médio sem conseguir ler ou escrever um texto simples. Assim, os resultados apontam a baixa qualidade de ensino no Brasil e um grande contingente de estudantes não alfabetizados apesar de terem passado uma média de 8 a 9 anos na escola ${ }^{(15)}$.

Ao tratar da campanha a favor de uma educação de qualidade, é possível apontar que:

[...] uma educação de qualidade será preciso mudar essa realidade atual em que a escola se encontra. Se quisermos obter resultados positivos, muita coisa, ainda, precisa mudar nas escolas, como por exemplo, se queremos uma escola e/ou uma educação de cunho igualitário, será preciso permitir que todos os atores envolvidos tenham voz e vez dentro e fora do âmbito educacional. Em outras palavras, é por meio da permissão da linguagem (fala) de todos os atores é que conseguiremos ouvir o outro e com isso, procurar mudanças, para entendermos o contexto social da escola de uma forma geral (RODRIGUES et al, 2017, p.33) ${ }^{(10)}$.

De acordo com Freitas e Pacífico (2), a partir da promulgação da Constituição Federal de 1988 e da Lei n 9394/96, Lei de Diretrizes e Bases da Educação Nacional (LDBEN), muitas políticas públicas educacionais foram implantadas com o objetivo de elevar a qualidade da educação no Brasil (1). Nesse sentido, a Lei n 9394/96, nos Artigos 62 e 63 dispõe sobre a garantia de formação continuada para professores em serviço. Algumas regiões, atendendo o que determina a legislação, tem garantido aos professores o direito à formação em serviço, no entanto, a oferta e a qualidade da mesma não atendem as diversas necessidades dos professores na prática pedagógica dentre de sala de aula (1).

A Lei de Diretrizes e Bases da Educação Nacional (LDBEN) ${ }^{(1)}$, estabelece ainda em seu Artigo 61 que a formação de profissionais da educação deve: 


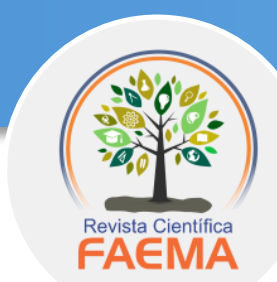

[...] atender aos objetivos dos diferentes níveis e modalidades de ensino e as características de cada fase do desenvolvimento do educando, terá como fundamentos $: 1^{\circ}$ - a associação entre teorias e práticas, inclusive mediante a capacitação em serviço; $2^{\circ}$ aproveitamento da formação e experiências anteriores em instituição de ensino e outras atividades (BRASIL, 1996, p.23) ${ }^{(1)}$.

Sobre a importância da formação continuada de professores, segundo Rodrigues et al. (10), os sujeitos formadores devem reconhecer a importância e a proporção que atinge o seu papel na vida dos sujeitos em formação, para que também se sintam tanto mais motivados na realização das atividades que the competem. Nesse sentido, os educadores são imprescindíveis na sociedade e assumem um papel primordial na transformação da sociedade e do meio em que vivem ${ }^{(10)}$.

São muitos os entraves que impedem que a formação continuada aconteça de modo efetivo dentro do espaço escolar. Isso fica evidenciado nas falas dos professores, que reclamam da falta de apoio do poder público para o exercício da profissão ${ }^{(10)}$.

Ao analisar a formação de professores a partir de diversas dimensões, é possível afirmar que:

[...] os poucos cursos que são oferecidos, além de não terem uma continuidade e serem muitas vezes mal planejados, não partem dos problemas vivenciados pelos professores [...] a formação continuada deve acontecer dentro da escola a partir de problemas específicos enfrentados pelos professores, porque são eles que devem ter habilidades específicas para lidar com as divergências do dia a dia em sala de aula (FREITAS; PACíFICO, 2020. p. 147) (2).

Dessa forma, de acordo com Rodrigues et al. (10), na formação inicial, o professor não detém todos os saberes necessários para que atenda todas as necessidades de uma sala de aula, as mudanças são constantes, sendo necessário que o professor busque o conhecimento, a formação continuada para ressignificar a prática pedagógica contribuindo para a melhoria do processo educacional.

Para Freire (7), a formação permanente dos professores é de grande e fundamental importância, tendo em vista que ela abre caminhos para a reflexão crítica sobre a prática. É a partir do pensamento crítico sobre a prática de hoje, de ontem que se pode melhorar a próxima prática. 


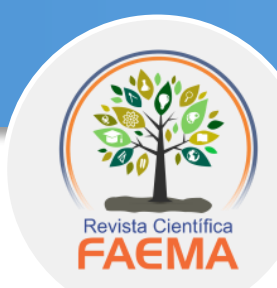

Assim, é necessário que os docentes saiam do comodismo de uma prática constante e imutável, e repensem suas ações dentro da sala de aula para que alcance de melhores resultados do processo ensino e aprendizagem dos estudantes. Nesse sentido, é necessário se perceber como ser em constante mudança, capaz de mudar, de promover transformações significativas na prática pedagógica ${ }^{(7)}$.

Dessa forma, “[...] faz-se necessário que estes sujeitos formadores, reconheçam e internalizem em si a importância e a proporção que atinge o seu papel na vida dos sujeitos em formação, para que também se sintam tanto mais motivados na realização das atividades que lhe competem" (10).

Entre os vários agravantes da formação continuada de professores, estudos apontam que:

[...] é a fragmentação dos estudos ou programas de formação oferecidos e a grande rotatividade de gestores pedagógicos, administrativos e professores. Já os professores indicam que os grandes problemas para a efetivação de uma formação continuada que surta resultados são a pouca sintonia entre a formação continuada e as reais necessidades a que são submetidos, a não participação dos professores nas decisões, falta de acompanhamento sistematizado da prática pedagógica, descontinuidade de políticas públicas direcionadas à formação continuada e baixos salários que levam a uma dupla carga horária (FREITAS; PACÍFICO, 2020, p. 143) ${ }^{(2)}$.

A discussão sobre a formação, segundo Freitas ${ }^{(5)}$, recai ainda sobre à temática das novas tecnologias e da educação a distância. Nos últimos anos, as Secretarias de Educação estaduais vêm expandindo-se em ritmo acelerado por todo o país a formação de professores em serviço através de convênios com universidades públicas à distância considerando a gravidade do grande número de professores que enfrentam desafios frente a prática pedagógica em sala de aula. Entretanto, os programas em grande maioria, priorizam as tutorias em ações fragmentadas e sem vinculação com os projetos pedagógicos das escolas.

Para Rodrigues et al. (10), atualmente a escola tem um papel muito importante na formação dos cidadãos. Entretanto, não cabe somente a escola esse papel, pois à família e a comunidade tem o dever como contribuição e auxílio no desenvolvimento social de cada indivíduo que passa uma boa parte de sua vida inserida no ambiente escolar (10). 


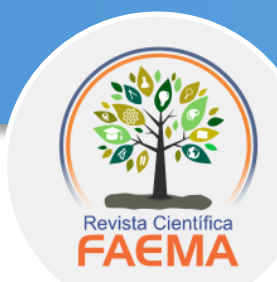

\section{Considerações Finais}

Os estudos apontam que a formação inicial do professor não é suficiente para uma prática pedagógica eficaz dentro de sala de aula. As mudanças ocorridas no cenário econômico, político, cultural, social e consequentemente no campo educacional coloca o professor frente a novos desafios, tendo em vista as novas demandas do processo educacional (2).

Nesse contexto, é possível destacar que a formação continuada é de fundamental importância como espaço coletivo de construção de novos saberes. Assim, será necessário repensar os programas de formação a partir das experiências formativas já existentes, transformando-as em ferramentas de investigação para novas pesquisas e possíveis mudanças na prática docente ${ }^{(6)}$.

Dessa forma, entende-se que efetivar a formação continuada dentro do espaço escolar não é uma tarefa simples devido as questões que impactam de forma significativa a prática do professor que se refere a falta de condições materiais e estruturais nas unidades escolares e falta de valorização profissional que afetam a vida dos profissionais ${ }^{(8)}$.

Nesse sentido, a efetivação de uma formação em serviço que atenda às necessidades dos professores representa um grande desafio, as experiencias enfrentadas devem servir como apontamentos para reflexão e análise e a partir desse norte, compreender a realidade da escola e vivenciar a dinâmica do processo de aprendizagem e as peculiaridades de cada escola ${ }^{(10)}$.

\section{Referências}

1 Brasil. Presidência da República. Lei n 9.394, de 20 de dezembro de 1996. Estabelece as diretrizes e bases da educação nacional. Brasília: Presidência da República; 1996.

2 Freitas SL, Pacífico JM. Formação continuada: um estudo colaborativo com professores do Ensino Médio de Rondônia. Interações, Campo Grande, MS. 2020;21(1):141-153. 


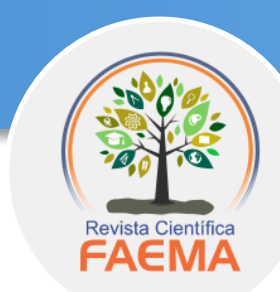

3 Cruz EC, Costa DB da. A importância da formação continuada e sua relação com a prática docente. Revista Científica Multidisciplinar Núcleo do Conhecimento. 2017;3(2):42-58.

4 Saviani D. A pedagogia no Brasil: história e teoria. Campinas: Autores Associados; 2008.

5 Freitas HCL de. Formação de Professores no Brasil: 10 Anos de embate entre projetos de formação. Educ. Soc., Campinas. 2002;23(80):136-167.

6 Peroni VMV. Implicações da relação público-privada para a democratização da educação no Brasil. In: Peroni VMV (Org.). Diálogos sobre as redefinições do papel do Estado e sobre as fronteiras entre o público e o privado. São Leopoldo: Oikos; 2015. p. 15-34.

7 Freire P. Pedagogia da autonomia: saberes necessários à prática educativa. São Paulo: Paz e Terra; 1996.

8 Altenfelder AH. Desafios e tendências em formação continuada. Construção psicopedagógica. 2005;13(10).

9 Libâneo JC. Organização e Gestão da Escola - Teoria e Prática. Goiânia: Alternativa; 2004.

10 Rodrigues PML, Lima WSR, Viana MAP. A importância da formação continuada de professores da educação básica: a arte de ensinar e o fazer cotidiano. Saberes Docentes em Ação. 2017;3(1).

11 Pimenta SG. Formação de professores: identidade e saberes da docência. In: Pimenta SG (Org.). Saberes pedagógicos e atividade docente. 2. ed. São Paulo: Cortez; 2000. p. 15-34.

12 Guimarães WS. Formação de professores: Saberes, identidade e profissão. 3. ed. São Paulo: Papirus; 2006.

13 Garcia CM. Formação de professores: para uma mudança educativa. Porto: Porto Editora; 1999.

14 Ruggeri MCC. Políticas Públicas de Formação dos Alfabetizadores. In: Anais do III EHECO - Universidade Federal de Goiás, Catalão, Goiás, 2015.

15 Soares MB. Letramento e escolarização. In: Ribeiro, VM (Org.) Letramento no Brasil. São Paulo: Global; 2003. p. 89-113. 